\title{
Say-Barber-Miller syndrome
}

INSERM

\section{Source}

INSERM. (1999). Orphanet: an online rare disease and orphan drug data base. Say-

Barber-Miller syndrome. ORPHA:3132

Say-Barber-Miller syndrome is characterised by the association of unusual facial

features, microcephaly, developmental delay, and severe postnatal growth retardation. 